\title{
Intestinal derivation for digestive complications of graft versus host disease in adult patients: A case series and review of the literature
}

\author{
Christophe Desprez ${ }^{1 *}$, Sylvie François ${ }^{1}$, Sylvain Thepot ${ }^{1}$, Christopher Nunes Gomes ${ }^{1}$, Norbert Ifrah ${ }^{1-3}$, Antoine Hamy ${ }^{4}$, Benjamin Morvant ${ }^{5}$, \\ Aurélien Giltat ${ }^{1}$, Aline Schmidt-Tanguy ${ }^{1-3}$, Mathilde Hunault-Berger ${ }^{1,3}$ and Corentin Orvain ${ }^{1-3}$ \\ ${ }^{1}$ Service des maladies du sang, CHU Angers, France \\ ${ }^{2}$ Federation hospitalo-universitaire, Grand Ouest against Leukemia, France \\ ${ }^{3}$ CRCINA - Unité Inserm U1232 F49000 Angers Université, France \\ ${ }^{4}$ Service de chirurgie digestive, CHU Angers, France \\ ${ }^{5}$ Service d'anatomopathologie, CHU Angers, France
}

\begin{abstract}
Background: Graft Versus Host Disease (GvHD) is a frequent complication of hematopoietic stem cell transplantation (HSCT). Acute GvHD can involve intestinal tract which requires temporary fasting in addition to immunosuppressive treatment. Surgical management of gastrointestinal (GI) GVHD is an unusual approach.

Objectives: Diversion stoma can help in healing the digestive tract during the acute phase of GI GvHD by keeping it free from any aggression. We report our experience of 6 adult patients with Gl GvHD who underwent intestinal surgery.

Study Design: Medical files of patients who experienced biopsy-proven GI GvHD between 01/01/2011 and 31/12/2019 in Angers University hospital were retrospectively reviewed and patients who underwent GI surgery were analysed. Informed consent was obtained from all patients.

Results: Between 2011 and 2019, 354 allogenic HSCT were performed and stage II to IV acute GI GvHD occurred in 42 patients. GI surgery and diversion stomas were required for 6 patients. Two surgeries were performed urgently for colonic perforation, 2 were performed for small bowel occlusion symptoms and 2 for uncontrolled GvHD symptoms despite medical treatment. All surgeries were performed safely. Diversion stomy could not prevent aGvHD progression and death in 2 patients. Additional treatment for GI GvHD was necessary in 1 patient while 3 patients did not receive any further treatment for GI GvHD after long-term follow-up. Two patients had successful bowel continuity restoration. Data from 29 patients who underwent GI surgery for acute GVH published so far are reviewed.

Conclusion: GI surgical interventions are rarely required in patients with GI GvHD. There is a lack of data on digestive surgery in GI GVHD, including follow-up data and efficiency on GVHD-related symptoms. The use of digestive surgery as diversion stoma appeared feasible for severe GI GVHD and seems to benefit some patients. This data should be confirmed in a larger study.
\end{abstract}

\begin{abstract}
Abbreviations: ADV: Adenovirus; ALL: acute lymphoblastic leukemia; ASCT: autologous stem cell transplantation; ATG: Anti-thymocyte Globulin; BM: Bone marrow; BPDCN: Blastic plasmacytoid dendritic cell neoplasm; CMML: chronic myelomonocytic leukemia; CR: Complete remission; DLBCL: diffuse large B cell lymphoma; ECP: extracorporeal photopheresis; FMT: faecal microbiota transplantation ; GI: gastrointestinal; GVHD: Graft Versus Host Disease; HHV6: Human Herpes Virus 6; HL: Hodgkin lymphoma; HSCT: Hematopoietic stem cell transplantation; MAC: myeloablative conditioning; MCR: metabolic complete remission; MHC: major histocompatibility complex; MMF: mycophenolate mofetil; MR: Minor response; MTX: Methotrexate; MUD: Matched unrelated Donor; NA: Not available; PBSC: peripheral blood stem cells; PD: Progressive disease; PMF: primary myelofibrosis; PR: Partial response; RIC: Reduced intensity conditioning; SBO: Small Bowell occlusion; SD: Stable disease; UCB: umbilical cord blood
\end{abstract}

\section{Introduction}

Allogenic hematopoietic stem cell transplantation (HSCT) is a potentially curative treatment for patients with high-risk hematological malignancies. Graft Versus Host Disease (GVHD) is a frequent and serious complication, which occurs among 35 to $45 \%$ of patients receiving a transplant from related donor and among 60 to $80 \%$ from unrelated donor, according to various studies. Acute GVHD is due to the alloactivation of donor T-cells, which results in the production of proinflammatory cytokines, and recruitment of other immune effector cells resulting in tissue injury [1]. It typically affects 3 restricted organs (skin, liver and gastrointestinal tract), whereas tissue involvement is much more extensive in chronic GVHD where all organs can be affected [2]. For patients who fail to respond to steroid therapy, there

${ }^{\star}$ Correspondence to: M. DESPREZ Christophe, Service des maladies du Sang, CHU Angers, 4 rue Larrey, F-49933 Angers Cedex 9, France, Tel: 024135 44 72; E-mail: christophe.j.desprez@gmail.com

Key words: hematopoietic stem cell transplantation, graft versus host disease, gastrointestinal surgery, small bowel obstruction, intestinal derivation, intestinal complications of graft versus host disease, stomy

Received: May 14, 2021; Accepted: May 21, 2021; Published: May 24, 2021 
is no standard second-line therapy that has been validated in welldesigned clinical trials with the recent exception of ruxolutinib [3]. Owing to the widespread tissue involvement that is a characteristic of most patients with GVHD, surgery is generally not considered. Therefore, surgical management for gastrointestinal (GI) GVHD is an unusual approach, reserved for patients with surgical emergencies such as intestinal perforation, intestinal occlusion or uncontrolled GVHD with severe GI bleeding or severe diarrhoea despite medical treatment.

We describe surgical management of 6 patients with intestinal GVHD in our institution and reviewed published cases of children [413] or adult [12-19] patients who underwent GI surgery for GI GvHD.

\section{Material and Methods}

A retrospective observational study was performed in the adult Hematology department of Angers University hospital, between $01 / 01 / 2011$ and $12 / 31 / 2019$. Patient lists were generated by medical record review, cross- referencing of GI histologically proven aGVHD diagnoses, and surgical interventions. We report herein our experience of 6 patients with GI acute GVHD who underwent GI surgery. Glucksberg classification was used to evaluate acute GVHD severity [20]. Urgent surgery was defined as any surgery performed for bowel perforation confirmed on CT scan. Adverse event of surgery was defined as any complication directly related to the surgical procedure. Response to surgery was assessed clinically by evaluating gastrointestinal symptoms and stool volume. The clinically relevant time point for GVHD response was 6 months after surgery. The criteria for defining responses for aGVHD were as previously reported [21]. Data collected were age at HSCT, type of hematological malignancie, previous chemotherapy, HSCT date, conditioning regimens, CMV donor and recipient status, graft source, GI GVHD date, treatment received for GVHD with starting date, surgery date, surgery complications, the need for intestinal resection, date of stoma closure, and viral co infection status. Informed consent was obtained from all patients.

\section{Results}

In Angers university hospital, 354 allogenic hematopoietic stem cell transplantations were performed between 01/01/2011 and $12 / 31 / 2019$. Acute GI GVHD occurred in $78(22 \%)$ patients and 42 (11.8\%) had a stage II to IV according to Glucksberg classification. Six patients underwent digestive surgical procedures due to GVHD within this 9-year period. Patient characteristics are presented in Table 1. Mean age at HSCT was 45 years old. Sex ratio was 0.5. Every patient had a controlled hematological malignancy at the time of
HSCT. They had received a median of 2 lines of chemotherapy for their initial hematological malignancy including 2 autologous SCT for patients 5 and 6. All HSCT were performed with matched unrelated donor (MUD). Majority of graft source was peripheral blood stem cells (4 PBSC, 1 BM and 1 umbilical cord blood). Three patients had a sex mismatch and 3 patients had CMV mismatched status. They all received reduced intensity conditioning except patient 3 who received myeloablative conditioning regimen. GVHD prophylaxis consisted of an anticalcineurin and mycophenolate mofetil, except for patient 3 who received methotrexate and anticalcineurin. Acute GI GvHD occurred in the first 100 days after graft reinjection for all 6 patients. They were all considered stage 4 according to Glucksberg classification because of ileus symptoms, fresh blood presence in diarrheas, or intestinal perforation. All patients were explored with endoscopy and CT scan before surgery but none had video capsule or enteroscanner performed. Systemic corticosteroids at $1 \mathrm{mg} / \mathrm{kg}$ to $2 \mathrm{mg} / \mathrm{kg}$ doses were used as first line treatment and proved ineffective for each patient. Patients 5 and 6 were diagnosed with 2 co-viral infections by HHV6 and adenovirus which required brincidofovir perfusion for patient 6 . There was no histologic evidence of cytomegalovirus (CMV) infection in any patient.

GI GVHD and immunosuppressive therapies are detailed in figure 1. Patients' surgical procedures and outcomes are summarized in Table 2. Surgery was performed urgently for colon perforation in two patients (patients 2 and 5), for small bowel occlusion in two patients (patients 1 and 6) and for uncontrolled GVHD symptoms such as important diarrhoea and gastrointestinal bleeding despite medical treatment in 2 patients (patients 3 and 4). For patient 6 , small bowell occlusion symptoms were linked to stenosis due to non-active GVHD. Both patients who required emergency surgery for colon perforation had colostomy (patients 2 and 5) with hemicolectomy for patient 5 while ileostomy were performed for the four other patients. None of these procedures were performed while patients were severely cytopenic (neutrophils range $1.3-13.1 \mathrm{G} / \mathrm{L}$, platelets range $62-225 \mathrm{G} / \mathrm{L}$ ) but all patients had malnutrition with low serum albumin level (range 19-29 $\mathrm{g} / \mathrm{L}$ ). No immediate post-surgical complications were observed but patient 6 experienced stomy intussusception few days after surgery which required reintervention and patient 5 had a small bowel occlusion because of intestinal adhesions which required reintervention about 2 months after the initial surgery.

GI derivation had no impact on the evolution of GI GvHD in patients 1, 2 and 3. Additional treatment for acute GI GVHD was necessary in patients 1 (faecal microbiota transplantation) and 3 (extracorporeal photophoresis) 70 and 88 days, respectively, after GI

Table 1. Characteristics of study patients at HSCT

\begin{tabular}{|c|c|c|c|c|c|c|c|c|c|c|}
\hline Patient & Gender & $\begin{array}{c}\text { Age } \\
\text { at HSCT } \\
(y)\end{array}$ & $\begin{array}{l}\text { Hematologic } \\
\text { malignancy }\end{array}$ & $\begin{array}{l}\text { Interval from } \\
\text { diagnosis to } \\
\text { HSCT } \\
\text { (m) }\end{array}$ & $\begin{array}{c}\text { Disease status } \\
\text { at HSCT }\end{array}$ & $\begin{array}{c}\text { Previous frontline } \\
\text { treatment }\end{array}$ & $\begin{array}{l}\text { Conditioning } \\
\text { regimen }\end{array}$ & Sex Donor & CMV status & Source \\
\hline 1 & $\mathrm{~F}$ & 41 & T-ALL & 5 & CR & 3 & RIC & M & D-/R- & PBSC \\
\hline 2 & M & 65 & BPDCN & 6 & $\mathrm{CR}$ & 2 & RIC & M & $\mathrm{D}-/ \mathrm{R}+$ & PBSC \\
\hline 3 & $\mathrm{~F}$ & 55 & PMF & 127 & SD & 1 & MAC & M & D-/R- & $\mathrm{BM}$ \\
\hline 4 & M & 66 & CMML & 7 & SD & 2 & RIC & $\mathrm{M}$ & $\mathrm{D}+/ \mathrm{R}-$ & PBSC \\
\hline 5 & M & 21 & $\mathrm{HL}$ & 13 & MCR & $2(+\mathrm{ASCT})$ & RIC & $\mathrm{F}$ & $\mathrm{D}+/ \mathrm{R}+$ & PBSC \\
\hline 6 & F & 24 & DLBCL & 20 & MCR & $2(+\mathrm{ASCT})$ & RIC & $\mathrm{F}$ & D-/R- & UCB \\
\hline
\end{tabular}

ASCT: autologous stem cell transplantation; ALL: acute lymphoblastic leukemia; BM: Bone marrow; BPDCN: Blastic plasmacytoid dendritic cell neoplasm; CMML: chronic myelomonocytic leukemia; DLBCL: diffuse large B cell lymphoma; GVHD: Graft Versus Host Disease; HL: Hodgkin lymphoma; HSCT: Hematopoietic stem cell transplantation; MUD: Matched unrelated Donor; PBSC: peripheral blood stem cells; PMF: primary myelofibrosis; UCB: umbilical cord blood; CR: Complete remission; MCR: metabolic complete remission; SD: Stable disease; RIC: Reduced intensity conditioning; MAC: myeloablative conditioning 
Table 2. Description of patient GVHD, surgical procedure and outcome

\begin{tabular}{|c|c|c|c|c|c|c|c|c|c|c|}
\hline Patient & $\begin{array}{l}\text { Time from } \\
\text { HSCT to } \\
\text { GI GVHD } \\
\text { (d) }\end{array}$ & $\begin{array}{l}\text { Time from } \\
\text { HSCT to } \\
\text { Surgery } \\
\text { (d) }\end{array}$ & $\begin{array}{l}\text { Surgical } \\
\text { Indication }\end{array}$ & Surgical complication & $\begin{array}{l}\text { Interval time to } \\
\text { complication } \\
\text { (d) }\end{array}$ & $\begin{array}{l}\text { Interval for new IS } \\
\text { treatment } \\
\text { after surgery (d) }\end{array}$ & $\begin{array}{l}\text { GVHD } \\
\text { response }\end{array}$ & $\begin{array}{l}\text { Interval from } \\
\text { surgery to stoma } \\
\text { closure } \\
\text { (d) }\end{array}$ & Alive & $\begin{array}{l}\text { Follow up } \\
\text { post HSCT } \\
\text { (d) }\end{array}$ \\
\hline 1 & 25 & 98 & SBO & none & - & 70 & PD & No closure & No & 398 \\
\hline 2 & 14 & 94 & $\begin{array}{l}\text { Colonic } \\
\text { Perforation }\end{array}$ & none & - & none & $\mathrm{PD}^{*}$ & No closure & No & 202 \\
\hline 3 & 95 & 274 & $\begin{array}{l}\text { GVHD } \\
\text { uncontrolled } \\
\text { symptoms }\end{array}$ & $\begin{array}{l}\text { intestinal adhesions } \\
\text { (after second surgery for } \\
\text { stoma closure) }\end{array}$ & $53^{*}$ & 88 & PD & $\begin{array}{l}506 \\
\text { (Failure } \\
\text { Ileocolectomy }+ \\
\text { colostomy) }\end{array}$ & Yes & 1867 \\
\hline 4 & 30 & 186 & $\begin{array}{l}\text { GVHD } \\
\text { uncontrolled } \\
\text { symptoms }\end{array}$ & none & - & none & $\mathrm{CR}$ & No closure & Yes & 1056 \\
\hline 5 & 22 & 87 & $\begin{array}{l}\text { Colonic } \\
\text { Perforation }\end{array}$ & $\begin{array}{l}\text { intestinal adhesions and } \\
\text { small bowel stenosis }\end{array}$ & 52 & 475 & PR & 248 & Yes & 2015 \\
\hline 6 & 20 & 459 & SBO & stomy intussusception & 38 & none & $\mathrm{CR}$ & 605 & Yes & 2538 \\
\hline
\end{tabular}

ADV: Adenovirus; GVHD: Graft Versus Host Disease; HHV6: Human Herpes Virus 6; HSCT: Hematopoietic stem cell transplantation; SBO: Small Bowell occlusion; PD: progressive disease; PR: partial response.

*Interval time from stoma closure and new colostomy (3 previous surgeries for occlusive intestinal episodes including anastomosis resection)

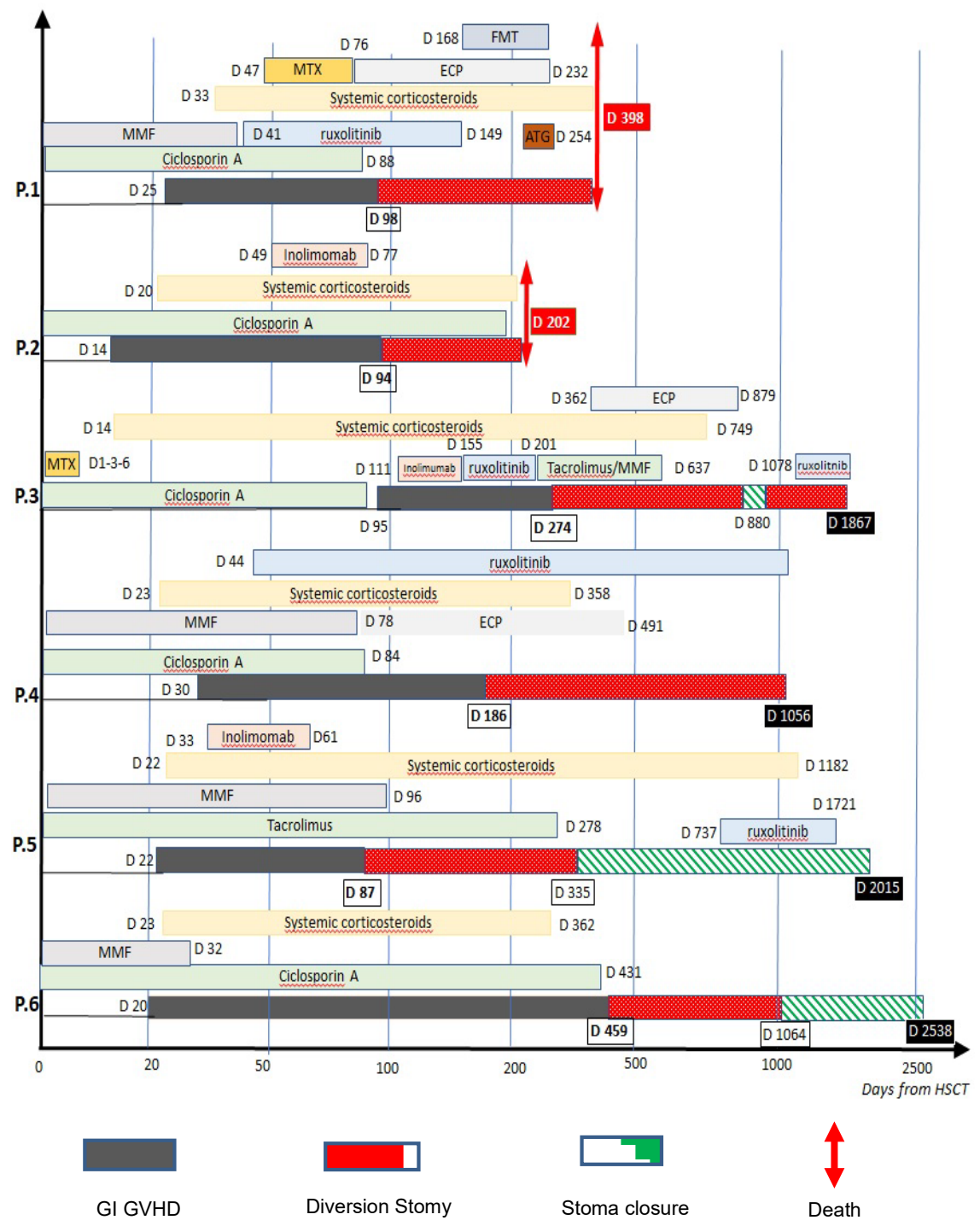

Figure 1. Chronology of immunosuppressive therapy and surgery for each patient

ATG: Anti-thymocyte Globulin; ECP: extracorporeal photopheresis; FMT: faecal microbiota transplantation; MMF: mycophenolate mofetil; MTX: Methotrexate 
derivation surgery because of uncontrolled diarrhea. No supplementary immunosuppressive treatment could be administered after surgery because of invasive aspergillosis in patient 2, even though he had uncontrolled acute GI GVHD, and he died 3 months after surgery due to GvHD. Patient 1 died 398 days after HSCT with uncontrolled GVHD and bacterial translocation.

On the contrary, GI derivation seems beneficial in patients 4,5 and 6. Indeed, no other treatment for GI GvHD was necessary after surgery because of complete (patient 4 and 6) or partial remission (patient 5) of GI GvHD 6 months after surgery. Noteworthy, ruxolitinib was used in patient 5 for late cutaneous GvHD from day 737 to day 1721 .

Stoma closure was performed successfully 248 and 605 days after GI derivation in patients 5 and 6 , respectively, but was unsuccessful for patient 3. For this patient, stoma closure performed 506 days after GI derivation was followed a month later by a third surgery because of intestinal adhesions and small bowel stenosis which required ileocolectomy and colostomy. At this time, there was no sign of histologically proven GvHD on the small bowel resection.

\section{Discussion}

Although intestinal aGvHD management is almost exclusively medical, a small subset of patients develops complications of intestinal GvHD that require surgical intervention. Surgical treatment of intestinal complications may thus be undertaken for perforation, hemorrhage refractory to medical, endoscopic or angiographic control, or obstructive symptoms due active or non-active GVHD. Managing patients with ileal or large bowel perforations conservatively, for example by simply inserting local drainage, suturing the perforation, or creating a proximal diversion (colostomy or ileostomy) is generally unsuccessful. Because of the multifocal nature of GVHD intestinal involvement, the whole perforated tract requires treatment, even if this entails total colectomy or a large segmental ileal resection. For identical reasons, a similar surgical approach is needed in case of gastrointestinal bleeding uncontrolled by conservative therapy.

There is a lack of data on digestive surgery in GI GVHD, including follow-up data and efficiency on GVHD-related symptoms. The feasibility of surgery during severe GI GVH has been previously evaluated in 29 patients [4-19] in the literature including 16 children [4-13]. Most surgical procedures were performed because of digestive perforation $[4,15,19]$, persistent digestive bleeding $[5,12,15,17]$ or small bowel occlusion $[4,6,10-13,17]$. Surgery was feasible despite GI GVHD but 8 out of the 29 patients reported so far died in the first month after surgery $[7,9,12-15,18]$. None of our patients died because of the surgery. This low rate of early mortality may be related to the reducedintensity conditioning used in 5 out of 6 of our patients which contrasts with patients reported in the literature where RIC conditioning was only mentioned in Cornell's report [16]. In addition, all procedures were performed after hematopoietic recovery in our patients. Beside the correction of digestive perforation, occlusion or bleeding, the effect of surgery on the evolution of GI GvHD has been rarely evaluated. For 3 out of 6 patients, no additional treatment for GI GvH was necessary with long-term survival without GI GvHD. The beneficial effect of surgery on digestive symptoms has also been reported in 14 out of 29 patients [5,6,10-12,15,17,19] but only Cornell, et al. [16], and Herr, et al. [13] reported on the positive effect of diversion stomy and the possibility of tapering immunosuppressant after surgery [16]. Stoma closure must be considered only when GVHD is completely controlled and patient requiring no more immunosuppressive treatment.
In conclusion, although rarely required, the use of digestive surgery with derivative stoma appeared feasible for severe acute GI GVHD. It could prevent digestive perforation by resting the digestive tract and help healing the digestive tract during an acute phase of GVHD by keeping it free from any aggression.

\section{Acknowledgements}

None to declare.

\section{Declaration}

- There are no financial conflicts of interest to disclose.

- Competing Interests: The authors have no conflict of interest to declare.

- Ethics: Informed consent was obtained.

- Availability of data and material: the datasets analyzed during the current study are available from the corresponding author on reasonable request.

\section{References}

1. Ferrara JLM, Levine JE, Reddy P, Holler E (2009) Graft-versus-host disease. Lancet 373: 1550-1561. [Crossref]

2. Filipovich AH, Weisdorf D, Pavletic S, Socie G, Wingard JR, et al. (2005) National Institutes of Health Consensus Development Project on Criteria for Clinical Trials in Chronic Graft-versus-Host Disease: I. Diagnosis and Staging Working Group Report. Biol Blood Marrow Transplant 20: 945-956. [Crossref]

3. Zeiser R, Burchert A, Lengerke C, Verbeek M, Maas-Bauer K, et al. (2015) Ruxolitinib in corticosteroid-refractory graft-versus-host disease after allogeneic stem cell transplantation: a multi-center survey. Leukemia 29: 2062. [Crossref]

4. Gutierrez CA, Raval MV, Vester HR, Chaudhury S, von Allmen D, et al. (2017) Surgical treatment of intestinal complications of graft versus host disease in the pediatric population: Case series and review of literature. J Pediatr Surg 52: 17181722. [Crossref]

5. Faraci M, Dallorso S, Morreale G, Dini G, Castagnola E, et al. (2004) Surgery for acute graft-versus-host disease of the bowel: description of a pediatric case. J Pediatr Hematol Oncol 26: 441-443. [Crossref]

6. Gassas A, Zaidman I, Schechter T, Doyle J (2011) Beyond gastrointestinal graft-versushost disease. A lesson to learn. Pediatr Transplant 15: E139-141. [Crossref]

7. Gavel G, Marven S, Evans MJ, Walker J, Vora AJ (2003) Obliterative enteritis complicating graft versus host disease. Bone Marrow Transplant 32: 1097-1098. [Crossref]

8. Grant CN, Nellis ED, Chahine AA (2014) A case of small intestinal cast causing SBO in complicated intestinal graft-versus-host disease. Pediatr Surg Int 30: 685-688. [Crossref]

9. Lieber J, Hauch H, Lang P, Handgretinger R, Blumenstock G, et al. (2012) Surgical management of stem cell transplantation-related complications in children. Pediatr Transplant 16: 471-479. [Crossref]

10. Yoon JY, Kim H, Kang HJ, Park KD, Shin HY, et al. (2012) Chronic graft versus host disease with small bowel obstruction after unrelated hematopoietic stem cell transplantation in a patient with acute myeloid leukemia. Korean J Hematol 47: 142145. [Crossref]

11. Kim Y, Moon SB (2015) Acute intestinal obstruction requiring surgery in pediatric malignancies: Summary of 7 cases. J Pediatr Surg Case Rep 3: 304-307.

12. Spencer GD, Shulman HM, Myerson D, Thomas ED, McDonald GB (1986) Diffuse intestinal ulceration after marrow transplantation: a clinicopathologic study of 13 patients. Hum Pathol 17: 621-633. [Crossref]

13. Herr AL, Latulippe JF, Carignan S, Mitchell A, Bélanger R, et al. (2004) Is severe intestinal chronic graft-versus-host disease an indication for surgery? A report of two cases. Transplantation 77: 1617-1620. [Crossref]

14. Anabtawi I, Abdel-Rahman F, Al Masri M (2011) Surgical complications related to hematopoietic stem cell transplantation. Eur J Surg Oncol 37: 576-582. [Crossref]

15. Chirletti P, Caronna R, Arcese W, Iori AP, Calcaterra D, et al. (1998) Gastrointestinal emergencies in patients with acute intestinal graft-versus-host disease. Leuk Lymphoma 29: 129-137. [Crossref] 
Desprez C (2021) Intestinal derivation for digestive complications of graft versus host disease in adult patients: a case series and review of the literature

16. Cornell RF, Palmer J, Komorowski R, Drobyski WR. Surgical resection as definitive treatment for refractory GVHD of the colon. Bone Marrow Transplant 47: 1366-1367. [Crossref]

17. Evans J, Percy J, Eckstein R, Ma D, Schnitzler M (1998) Surgery for intestinal graftversus-host disease: report of two cases. Dis Colon Rectum 41: 1573-1576. [Crossref]

18. Irani JL, Cutler CS, Whang EE, Clancy TE, Russell S, et al. (2008) Severe acute gastrointestinal graft-vs-host disease: an emerging surgical dilemma in contemporary cancer care. Arch Surg 143: 1041-1045. [Crossref]
19. Palaniappa NC, Doyon L, Divino CM (2012) Colonic perforation in graft versus host disease: a case report. Int Surg 97: 14-16. [Crossref]

20. Glucksberg H, Storb R, Fefer A, Buckner CD, Neiman PE, et al. (1974) Clinical manifestations of graft-versus-host disease in human recipients of marrow from HL-Amatched sibling donors. Transplantation 18: 295-304. [Crossref]

21. Messina C, Locatelli F, Lanino E, Uderzo C, Zacchello G, et al. (2003) Extracorporeal photochemotherapy for paediatric patients with graft-versus-host disease after haematopoietic stem cell transplantation. Br J Haematol 122: 118-127. [Crossref]

Copyright: (C2021 Desprez C. This is an open-access article distributed under the terms of the Creative Commons Attribution License, which permits unrestricted use, distribution, and reproduction in any medium, provided the original author and source are credited. 